\title{
The role of endoscopic ultrasonography (EUS) in contemporary diagnosis of gastrointestinal diseases
}

\section{Rola ultrasonografii endoskopowej (EUS) we współczesnej diagnostyce chorób układu pokarmowego}

\author{
Jacek Kiełtucki, Katarzyna Wawrzyniec \\ Department of Department of Internal Medicine and Endoscopy Unit, Independent Public Health Care Center, Staszów, Poland \\ Head of the Department: Jacek Kiełtucki MD, PhD
}

Key words: endoscopic ultrasonography, fine-needle aspiration, diagnostics.

Słowa kluczowe: ultrasonografia endoskopowa, biopsja aspiracyjna cienkoigłowa, diagnostyka.

\begin{abstract}
Day by day endoscopic ultrasonography (EUS) is becoming an essential diagnostic method for the assessment of solid lesions of the pancreas, cysts, pseudocysts and cystic tumours of the pancreas, enlarged mediastinal lymph nodes, staging of gastric cancer and rectal cancer, as well as lung or subepithelial tumours in the gastrointestinal tract. The ability to use this diagnostic method presents many challenges for performing specialists, from the organisation of the EUS surgery to maintaining its activity in a proper technical aspect, as well as the continuous improvement of staff qualifications. Endoscopic ultrasonography has revolutionised the practical aspects of gastroenterological practice and oncology. Particularly, EUS-guided fine-needle aspiration biopsy (EUS-FNA) of various pathologies in the gastrointestinal tract has provided invaluable effects and opportunities. This technique is becoming more and more available in Poland, creating a unique challenge to its practice.
\end{abstract}

\section{Streszczenie}

Ultrasonografia endoskopowa (EUS) staje się z dnia na dzień kluczową metodą diagnostyczną zmian litych w trzustce, torbieli, pseudotorbieli i guzów torbielowatych trzustki, powiększonych węzłów chłonnych śródpiersia, zaawansowania raka żołądka, odbytnicy, jak również nowotworów płuc i zmian podnabłonkowych w przewodzie pokarmowym. Technika ta stawia przed wykonującymi badanie wiele wyzwań - zorganizowanie pracowni EUS, utrzymanie jej działania na należytym poziomie technicznym czy stałe podnoszenie kwalifikacji personelu. Ultrasonografia endoskopowa zrewolucjonizowała praktyczne aspekty diagnostyki gastroenterologicznej i onkologicznej, zwłaszcza biopsja cienkoigłowa kontrolowana ultrasonografią endoskopową (EUS-FNA) różnego rodzaju zmian w obrębie przewodu pokarmowego daje nieocenione efekty i możliwości. Metoda ta jest coraz bardziej dostępna w Polsce, zwiększają się również możliwości jej praktycznego doskonalenia.

\section{Introduction}

Although classic ultrasonography is still an invaluable diagnostic tool, a new version of this modality combined with endoscopy, known as endoscopic ultrasonography (EUS), provides even greater possibilities. The works on ultrasonographic ultrasound diagnostics began in the early 1950s. Now, after 60 years, it is one of the basic tools used for the imaging of many organs and cardiovascular system diagnostics. Ultrasonography is a complementary method in comparison with traditional imaging techniques such as X-rays, radioisotopes, computed tomography, or magnetic resonance. It also has some unique properties compared with the mentioned imaging methods. Its most important quality is the non-ionising nature of ultrasonic waves, and the low cost of the examination. According to current levels of knowledge and research there are no side effects of the intensity of ultrasonic waves used in ultrasonography. An important advantage of this ultrasonographic technic is the almost real-time of the received ultrasonograms. The resolutions of this tool, i.e. its ability to distinguish and detect small lesions in organs, is about half a millimetre. This means that ultrasonography matches the innovation level of the latest generation tomography and magnetic resonance imaging methods. Comparing with the older tools such as 16-slice computer tomography, which can detect tumours greater than $2 \mathrm{~cm}$, the new EUS apparatus is much more effective. Of course, ultrasonography also has some drawbacks. The ultrasonic waves used in the ultrasonography 
(USG) technique are almost completely reflected at the border of gas filled areas. However, continued progress in the latest machines' resolution and postprocessing allows assessment of structures such as intestines, lungs, or bones using this technique. Reflection of ultrasonic waves from different biological structures is the basis for tissue imaging in ultrasonographic methods. The reflection depends mainly on the elastic properties of the tissues. And this is the feature that differentiates ultrasonic methods from radiological ones - in the latter, the tissue density has a major impact on its distinctness. The echo phenomenon (wave reflection) is the basis for the visualisation of internal structures of the body. The echo occurs when the wave reflects from the boundaries of two centres that differ from each other in their acoustic impedance (pressure to sound speed ratio). The volume of the echo depends on how much of the wave energy is reflected and how much of the energy penetrates through the boundaries between different tissues and organs. When the wave reflects from the boundaries of centres that differ in acoustic impedance, partial wave reflection occurs, which indicates the presence of the tissue differing from the surrounding environment. The received echoes, amplified and processed, are displayed on the monitor. The image quality depends on the three parameters: spatial resolution, temporal resolution, and dynamic contrast.

Endoscopic ultrasonography, echo-endoscopy (EUS) was created in the early 1980s. Initially, it was available only in a few centres, but in the 1990s it developed and was introduced in more units and took an important position in gastroenterology diagnostics. In accordance with current standards, echoendoscope prototypes were very unwieldy to use. Because production of the first echoendoscope was before the classic video-endoscope era, the first devices were created on the basis of optical fibre units and in the straight-ahead optics position. By today's standards, the ultrasound component of EUS was extremely primitive. Currently, endoscopic ultrasonography enables precise visualisation of the gastrointestinal wall and the surrounding organs and structures, primarily the pancreas and bile ducts, and also more and more other organs and structures due to the continuous improvement of its imaging quality. It is an essential part of diagnostic algorithms of many neoplastic and non-neoplastic gastrointestinal tract diseases. Unfortunately, in Poland, as well as in other countries, it is not yet commonly available. This is due to the learning curve, which is flat and amounts to about 7 years.

The examination is performed using an ultrasonographic probe, which is an integral part of a special endoscope; fine ultrasonographic probes are used much less frequently. The probe is placed in close proximity to the examined structures, which allows avoidance of some of the problems and limitations that are common in classic ultrasonography. In this way an ultrasound wave of higher frequency can be used and a higher resolution image can be obtained. It should be remembered that the penetration depth of the ultrasonographic wave is inversely proportional to its frequency; in EUS only evaluation of organs and structures lying a few centimetres from the probe is possible. Biopsy needle or other instruments, introduced through the echoendoscope channel, are visible in the EUS image. This enables sample collection from the interior of the visible changes for microscopic examination as well as EUS-guided therapeutic and diagnostic procedures. Among the therapeutic procedures there it be mentioned that recently EUS has also started to be used for pseudocyst drainage, necrosis in acute pancreatitis, or to drain the common bile duct or pancreatic duct. Contrast enhanced imaging modalities, as well as use of ultrasonographic probes with elastography option, have an increasingly important role [1].

\section{Intramural tumours and submucosal lesions}

The mucous membrane bulges encountered during endoscopy may be formed in each layer of the wall of the gastrointestinal tract (intramural) or outside the wall (external). They are usually detected incidentally during endoscopy. Differential diagnosis includes a number of benign and malignant non-epithelial tumours of the gastric wall, intramural vessels, and extrinsic compression from external structures. Endoscopic ultrasonography has introduced a breakthrough in characterising such changes. Endoscopic ultrasonography allows us to understand whether the change arises from the wall of the gastrointestinal tract (intramural) or from the external structure (external). The exterior changes may be adjacent normal structures (e.g. spleen, aorta, gallbladder) or pathological structures (e.g. splenic artery aneurysm, cysts, tumours). Distinction between external and intramural changes is not difficult, unless there is an invasion into the wall of the gastrointestinal tract. Endoscopic ultrasonography allows us to determine the origin layer of intramural lesions, which is very important in making diagnosis. For example, stromal tumours typically develop from the specific muscle layer or muscle mucosa, whereas lipomas typically develop from the submucosal layer. Echogenicity, vascularisation, margins, the size of the change, and the lack or presence of the adjacent lymph nodes also helps to narrow the differential diagnosis. Endoscopic ultrasonography -guided aspiration biopsy or Tru-cut biopsy are invaluable in many diagnostic cases. The basic features that need be specified are: layer of origin or external origin, size, echogenicity, and vascularisation. Echogenicity can be described as:

- anechoic - the echogenicity of water or clear liquid (i.e. black, without the internal echo). Anechoic 
lesions are usually associated with acoustic amplification, which is a brighter echo, placed behind the fluid-filled structure. The typical examples are cysts, vessels, and gallbladder.

- hypoechoic - echogenicity, which is equal to or lower than in the second (lamina propria) and in the fourth layer of the wall (the muscularis propria). The typical examples are myomas, gastrointestinal stromal tumours (GIST), or mucin-filled cysts.

- hyperechoic - echogenicity that is equal to or higher than in the first (surface mucosa), in the third (submucosal), and in the fifth layer (serous membrane). The most common example is lipoma.

- isoechoic - echogenicity that is equal or nearly equal to the involved lesion layer [2]. As a rule, the ability of EUS to distinguish submucosal lesions is variable. As a result, histology still is considered the "gold standard".

A prospective study assessing the accuracy of EUS in the characteristics of 100 patients with submucosal lesions showed that the results of the EUS enabled correct prediction of the lesion type only in $48 \%$ of cases confirmed by biopsy [3]. Most errors occurred in hypoechoic lesions in the third and fourth layer, which include: carcinoid, GIST, and pancreas lesions. Another study compared the results of endoscopic resection or biopsy after unroofing for 54 submucosal lesions with EUS results [4]. The total accuracy of EUS in determining the origin layers and location of lesions was $80 \%$; six lesions in the gastrointestinal wall were located deeper than was estimated by EUS, and five of them were more superficial. The results obtained in EUS and pathologic examination were consistent in $74 \%$ of cases [4]. In another study, 22 patients underwent EUS before gastric subepithelial lesion endoscopic resection. Endoscopic ultrasonography alone correctly diagnosed 10 (46\%) lesions. Incorrectly diagnosed lesions were: pancreatic lesions $(n=5)$ and gastritis cystica profunda $(n=2)$ [5]. Normal anatomical structures and extramural benign or malignant tumours may compress the gastrointestinal wall and imitate intramural tumours. Accidental lesions are increasingly detected in patients by increasingly used computed tomography (CT) or magnetic resonance imaging (MRI) scan. Endoscopic ultrasonography can help in further characteristics of such cases. In EUS, the normal five-layer structure of the gastrointestinal wall is seen. Unique echo-features differ depending on the type of identified lesion. As an example, the spleen vessels on Doppler examination are anechoic structure with flow. The spleen may appear as having homogenous hypoechoicity. Pancreas pseudocysts originate from the pancreatic region, and are commonly hypoechoic or anechoic. Endoscopic ultrasonography has introduced a breakthrough in subepithelial change characteristics. It complements other diagnostic methods (and treatment) of these lesions.
The sonographic appearance of some of the other methods is very suggestive for diagnosis, while in other cases EUS provides additional information for the obtained by other methods.

\section{Endoscopic ultrasonography in intraductal gallstones}

Good results of EUS in detecting intraductal gallstones of diameter less than $1 \mathrm{~cm}$, occurring in nonextended bile ducts, deserve special attention. In such cases, classic USG and computed tomography are evidently less effective diagnostic tools. The evaluation of the number of stones and their location in bile ducts, as well as the diameter of bile ducts, made in EUS are very precise. Evaluation of the diameter of the stones is the only aspect that is sometimes poorly estimated by EUS; this is caused by the existence of acoustic shadows. The hypothesis, based upon the previous work and use of the statistical method of logistic regression, is that the endosonographic finding of choledocholithiasis is the most reliable single predictor confirming its presence. It is much more reliable than clinical, biochemical, and morphological (e.g. the stones' diameter in USG) criteria. It is worth mentioning that the problem in intraductal gallstones diagnosis is not only the size of the plaque but also its density. In cases of density close to the density of bile the diagnosis can be difficult. Currently designed diagnostic schemas for patients with suspected choledocholithiasis should always take EUS into account. Gradual progress in Polish medicine, represented by a slow but steady increase of endosonographic examination availability, gives reason for hope that such schemas will become widely available in the near future. Based on EUS, choledocholithiasis diagnosis should indicate endoscopic retrograde cholangiopancreatography (ERCP) and endoscopic sphincterotomy, whereas the absence of choledocholithiasis in EUS confirms with high accuracy its non-occurrence. In such cases we can avoid performing ERCP, which is associated with the risk of serious complications.

In the publication "Endoscopy", Polish researchers from the Gastroenterology Department, Center of Postgraduate Medical Education (CMKP), published the results of a randomised trial that assessed the effectiveness of treatment and complications risk in patients with suspected choledocholithiasis, treated with ERCP, in comparison with patients in whom the decision of endoscopic treatment was conditional on the results of EUS [6].

According to the recommendations of the British Society of Gastroenterology from 2008 [7], patients with suspected cholelithiasis should be diagnosed using non-invasive EUS. Although ERCP has a high sensitivity (90\%) and specificity (98\%) $27-67 \%$ of the examinations performed because of suspected cholelithiasis give negative results. Similar recommenda- 
tions were also formulated by other authors. Baron and Irani believe that the most effective method to prevent acute pancreatitis after ERCP is avoiding diagnostic retrograde cholangiopancreatography [8].

The best alternative followed by no complications is endoscopic ultrasound of bile duct, performed using a 7.5 and $12 \mathrm{MHz}$ head. The results of extensive meta-analysis (with 2673 patients) [9] show that sensitivity and specificity of EUS is 94\% and 95\%, respectively. Considering the resolution of modern endosonographs $(0.1 \mathrm{~mm})$, the authors also believe that this method is a new gold standard for diagnosis of the biliary ducts. The data collected in the metaanalysis do not allow us to determine if the sensitivity and specificity of endo-ultrasonography depends on the size of the stones. However, according to another two authors [10], the sensitivity and specificity of endo-ultrasonography does not depend on the size of stones, in contrast to MRCP and ERCP, the sensitivity and specificity of which decrease non-linearly with the dimensions of the stones in the ducts.

The increasing use of EUS in the diagnostics of intraductal gallstones has led to discussions on the optimal diagnostic-therapeutic scheme. In the times when ERCP was a basic diagnostic procedure, in case of confirmation of the stones presence the diagnostic examination was converted into therapeutic procedure by performing an incision of the Vater papilla and removal of the stones. Endoscopic ultrasonography is just a diagnostic procedure. Most authors [11] believe that the optimal diagnostic and therapeutic strategy in patients with choledocholithiasis - after endosonographic confirmation of the stones' presence - is simultaneous surgical ERCP with removal of the stones. A systematic review of publications carried out by Petrov and Savides [12] involved 191 published prospective studies on the diagnosis and treatment of intraductal gallstones in a group of 2500 patients. It showed that the optimal diagnostic-therapeutic scheme in suspected choledocholithiasis is endoscopic ultrasound combined with therapeutic ERCP, in the case of confirmation of choledocholithiasis. This scheme allows avoidance of unnecessary ERCP in $67.1 \%$ patients, thereby significantly reducing the rate of complications.

\section{Focal pancreatic changes}

Endoscopic ultrasonography plays an increasingly important role in differential diagnosis of inflammatory tumours (focal autoimmune pancreatitis, tumours formed in chronic pancreatitis) and malignancies (adenocarcinoma, metastasis) of the pancreas. The mentioned pancreas focal lesions are often difficult to interpret just on the basis of the CT scan result. The high resolution of the pancreas image obtained by EUS makes it the most accurate diagnostic and staging method in inflammation, cysts, and cancer diseases of this organ. The greatest difficulty is differentiation between cancer and focal inflammation in B-mode sequence, particularly in advanced chronic pancreatitis, where the sensitivity of the method is about $75 \%$. Using the endoscopic ultrasound/fine needle aspiration (EUS-FNA) technique to diagnose solid pancreas tumours increases this index to $92 \%$ and its specificity from $79 \%$ to $92 \%$ [13]. The sensitivity of EUS-FNA is lower when the tumour is surrounded by inflammatory changed parenchyma in chronic pancreatitis, compared to research conducted on pancreas without inflammation. The disadvantage of EUS-FNA is the difficulty in conducting an examination in cases of vessel interposition, duodenal stenosis, or substantial tumour hardness, which decrease its specificity. Another failing of EUS is the dependence of its results on the operator.

The EUS elastography is another method that is very helpful in diagnosis of abnormalities localised in pancreas parenchyma, and it is based on the assessment of the rate of deformation resulting from distinct changes in tissue elasticity during inflammation, fibrosis, or tumour proliferation. The sensitivity of EUS elastography in differentiating focal lesions is $92 \%$ (100\% for malignant tumours) and specificity is $80 \%$ and $92 \%$, respectively [14].

Endoscopic ultrasonography is also helpful in diagnosis of another pathology - autoimmune pancreatitis. The image obtained by CT, showing the focal or dispersed organ enlargement without Wirsung's duct broadening, lack of calcifications or pseudocysts and enlarged gland ("sausage-shaped") with hypoechoic, patchy, heterogenous-looking parenchyma suggest autoimmune inflammation. The basic function of EUS usage in this case is EUS-FNA [15].

In recent years EUS has become a very useful method for pancreatitis detection, helping to define its aetiology (choledocholithiasis considering microcalculosis, chronic pancreatitis, tumours), while other imaging techniques are not sufficient and are not good predictive methods in terms of prognosis considering the severity and consequences of acute pancreatitis. In the analysis by Bhutani et al., patients who had "coarse" echotexture of the pancreatitis required shorter hospitalisation (on average 2.6 days) compared to those in whom it was "fine" or "normal" [16]. In the assessment of acute biliary pancreatitis, EUS has sensitivity of $91-100 \%$ and specificity of $85-100 \%$ in stones detecting. It is believed that in case of acute pancreatitis with indirect probability of common bile duct stones, EUS is a safe method, which helps to avoid unnecessary diagnostic ERCP [17]. Abdominal ultrasound has significant limitations concerning presentation of the distal common bile duct, but EUS provides high quality of its imaging from Vater's papilla to liver hilus, causing significantly fewer complications than ERCP. Endoscopic ultrasonography 
has a high sensitivity in detection of microstones or biliary sediment in patients with "idiopathic" pancreatitis, who had negative traditional transabdominal ultrasound result. Tumours resulting in infiltration or compression on the bile ducts can also cause recurrent pancreatitis. Endoscopic ultrasonography successfully detects tumour masses having a diameter of $<2.0 \mathrm{~cm}$, duodenal bulb oedema, neoplastic infiltration, and polyps in the area. In addition, EUS is also applicable in chronic pancreatitis. Imaged interstitial and ductal changes correlate with the histological pancreas fibrosis degree. Interstitial changes include hyperechoic foci, bands, lobes, cysts, and calcification. The main abnormalities typical for chronic pancreatitis, observed in EUS are: dilation of the main pancreatic duct, irregularity and hyperechogenicity of its margins, and manifestation of its lateral branches. One of the most important issues in chronic pancreatitis is early diagnosis, which enables implementation of appropriate treatment. The most accurate diagnostic test is histological evaluation of the collected material, but its collection is connected with an invasive procedure carrying the risk of complications. Endoscopic ultrasonography is an alternative method, giving results which correlate with the parenchyma fibrosis degree obtained in histopathological examination. Two studies took into account nine criteria (four ductal and five interstitial) specific to chronic pancreatitis, confirming the diagnosis cut-off point of four or more characters $[18,19]$. Endoscopic ultrasonography can confirm the chronic inflammatory process of the pancreas at an early stage, when CT is not yet visible parenchyma atrophy, or calcification. Unfortunately, the increased sensitivity may entail specificity lowering, which occurs during imaging of predictive changes by EUS in chronic pancreatitis with no clinical signs. The most common false positive results were reported in obese male patients chronically abusing alcohol and smoking cigarettes [19].

In summary, in the current algorithm, CT is still the gold standard in the diagnosis of chronic pancreatitis although its non-diagnostic result suggests using EUS as a method particularly useful in visualising less advanced changes. The EUS-FNA is an auxiliary method in diagnosis of focal lesions in the pancreas. It is a digital image analysis (DIA), which reduces the role of the endoscopist in EUS image interpretation, thus unifying the obtained results. Digital image analysis analysis takes into account an algorithmic quantitative analysis including the colour, arrangement, and pattern of individual pixels [20]. The EUS elastography described above assesses tissue hardness by measuring its response to compression. The deformation can be assessed quantitatively and colourimetrically and can be overlaid on the sequence B-mode image. Another modification is contrast strengthening of EUS by intravenous contrast applications, for example
Sonovue, which improves differentiation between benign and malignant lesions, increasing the sensitivity from $73 \%$ to $91 \%$ and specificity from $83 \%$ to 93\% [21]. Pancreatic cancer is one of the cancers with the worst prognosis. Difficulty in early detection of small changes means that the average 5-year survival is only $5.5 \%$ [22]. Endoscopic ultrasonography is a diagnostic method that has a higher sensitivity than CT and MRI. Endoscopic ultrasonography and MRI are considered to be the best methods for early diagnosis of focal lesions in the pancreas, with emphasis on the increasing advantage of EUS, which has a high sensitivity and specificity as well as allowing biopsy.

\section{Gastric cancer}

Endoscopic ultrasonography is considered to be the most appropriate method in determining the advancement of locoregional gastric cancer. Endoscopic ultrasonography gives the possibility of retrieving a sample for histopathological examination from suspicious intramural and submucosal lesions (EUSFNA). Consequently, it has become an extremely helpful method in making therapeutic decisions. In addition to the accurate determination of tumour infiltration in the stomach wall, EUS can present the involvement of regional lymph nodes, mediastinum lymph nodes, distant metastases primarily in the lobe of the left liver or adrenal glands. The sensitivity of the method is higher in defining metastases in more advanced changes in lymph nodes classified as pN2 and $\mathrm{pN} 3$ (13 correctly classified from 16), compared to pN1 changes (17/23, respectively) and lesions located in the gastric fundus and cardia $(24 / 25)$ than in the gastric body (25/34 correctly classified by the EUS). Ambiguities in visualising positive lymph nodes from more distant compartments are more noticeable during EUS. D1 and D2 regions are clearly visible, but analysis of the D3 area is difficult. Attempts to include a smaller diameter of change suspected to be a metastasis in lymph node into the classification did not improve the results [24].

Endoscopic ultrasonography is a very accurate method allowing differentiation between locally limited and advanced forms of the disease. Polkowski et al. correctly diagnosed 40 of 43 cases of locally advanced gastric cancer in one study. That result demonstrated 93\% sensitivity of the method. As mentioned above, greater probability of a correct result was observed in the tumours of gastric fundus and cardia (27/28 correctly classified) than in those located in the gastric body (28/34, respectively) [24].

Excessively high classification of assessed lesions is more common than underestimation of tumour stage during EUS. The revaluation of depth infiltration in the gastric wall by smaller pT1-pT2 tumours is especially noticeable. This might be due to incorrect interpreta- 
tion of secondary inflammatory, fibrous, and necrotic changes of surrounding tumour tissue by the operator.

\section{Endoscopic ultrasound-fine needle aspiration}

Endoscopic ultrasonography has evolved from a method of diagnostic imaging to a tool that can also be used for invasive diagnostic and therapeutic procedures. These advances are mainly due to the use of linear scanning instruments that can place the instrument in an ultrasound plane of view that allows different interventions. The ability to guide a biopsy needle to changes that are too small to identify by CT or MRI, or are too difficult to access using percutaneous biopsy, provides an important role for EUS in many clinical situations. Indications for the use of fine-needle aspiration biopsy under the control of EUS (EUS-FNA) are mucosal and submucosal changes in which previous conventional endoscopic biopsies were nondiagnostic. This procedure is most commonly used for the sampling of structures such as lymph nodes, changes in the pancreas, liver, adrenal glands, and bile ducts. It is also used to collect peritoneal and pleural cavity fluid. There are various EUS tools. Most of them are similar to standard endoscopic instruments in that they have biopsy channels and the ability to record and optic capabilities. They differ from conventional endoscopes in that they have a sophisticated ultrasound transmission and reception capacity at the tip of the instrument.

Linear endoscopes are perfect tools to perform biopsy under the control of EUS (EUS-FNA) because such a system allows for the visualisation of the needle in real time as it is inserted into the periluminal space. This instrument has an electronic ultrasonic system that scans into the long axis of the endoscope in one line of imaging and biopsy channels. As a result, the needle is moved through the biopsy channel to the target tissue in the ultrasound plane and is thus visible on the ultrasound image in real time during the biopsy. Several needles are available to perform EUS-FNA (Cook Endoskopia Inc., Winston-Salem, NC; GIP Mediglobe, Tempe, AZ, Olympus Inc., Center Valley, PA, Boston Scientific, Natick, MA). Each uses a set of catheter mechanisms attached to a handle fastened to the anchor of the echoendoscope. The thickness of the needle ranges from 19 to $25 \mathrm{IU}$ with a penetration depth of $10 \mathrm{~cm}$. There is no evidence that a needle with a larger diameter provides greater diagnostic accuracy. All needles have a central bevelled tube so as to fit to the tip of the needle, which increases the clarity of the device. Needle gauge of 19 is quite rigid, and it can be difficult to handle in the duodenum with a sharply curved instrument. Some needles were developed to perform so-called 'core' biopsies: EchoTip ProCore, Cook Endoscopy [25]. Two other manufacturers have created needles with side openings. The idea of the designer was that tissue would "enter" the side openings of the needle by suction and then be cleaved when the needle is moved back and forth. The needle should be carried to the target tissue under direct guidance with EUS. Prior to insertion of the needle, one should get a view of the Doppler flow to safely get around blood vessels. Sometimes, fast "stabs" are needed to get through the muscularis propria and/or enter the change. After the needle is located in the target change, the probe is removed and negative pressure by a $10 \mathrm{ml}$ syringe is applied. The negative pressure must be released before removing the needle. This should be done by releasing the plunger and not making it return to the neutral position. Reduced negative pressure (1 to $2 \mathrm{ml})$ may result in fewer blood aspirates, particularly for vascular tumours (e.g. neuroendocrine one) or lymph nodes. One study suggests that at the time of lymph node's biopsy cellularity was increased with suction, but it did not increase the probability of a correct diagnosis [26]. The location of aspirations in the lymph nodes does not affect the accuracy of the results. Additional data indicate that negative pressure arising from the withdrawal of the probe may be sufficient to take samples and provide better diagnostic cellular elements [27]. Aspirated material should be prepared by "smearing" it on a glass slide that has been previously labelled with the patient's identification mark. One glass slide should be dried by air for interpretation on site, and a second one should be fixed with spray, e.g. Cytofix. In patients where differential diagnosis lymphoma is suspected, material should be obtained in addition to the preservative solution, which allows further flow cytometry to be performed. Another sample should be collected in the so-called 'cell block'. Then, in order to remove remnants of the material, purging the needle with air should be performed, which provides the next diagnostic samples. It would be ideal if a pathologist or cytopathologist was present during the procedure. Such a person could indicate when a representative sample of the cell has been obtained. The role of fine-needle aspiration biopsy under the guidance of EUS is invaluable in diagnosing and differentiating many lesions. These include solid lesions in the pancreas in correlation with pancreatic neuroendocrine tumours. Endoscopic ultrasound-fine needle aspiration is an excellent diagnostic tool for cysts and pseudocysts in the pancreas, as well as peripancreatic ones. It allows the analysis of tissue fluids as well as detailed image information. Up to $10 \%$ of pancreatic cysts are neoplasms, many of which are initially wrongly diagnosed as pseudocysts. Some cystic pancreatic tumours are malignant (cystadenocarcinoma) or have the potential to become malignant (e.g. mucinous pancreatic cancer, intraductal papillary mucinous), while others have a low potential of malignancy or are benign (e.g. serous cystadenocarcinoma). The distinction between these subtypes can sometimes be made on morpho- 
logical criteria only, but no endosonographic features have been proven to be consistently reliable in distinguishing between benign and malignant lesions. Sampling of tissue or fluid from a cyst may be useful in patients in whom a diagnosis is uncertain. Having proved helpful in the determination of tumour antigens [28], fluid viscosity, mucin-producing cells [29], or analysis of genetic mutations associated with cancer [30] are very helpful. High concentrations of amylase suggests pseudocysts or retention cysts although there are case reports of elevated amylase levels in patients with cystic neoplasms [30]. Metastatic tumours of the pancreas can also be visualised and subjected to biopsy. Numerous studies confirm that endosonography is useful to evaluate peri-intestinal and mediastinal lymph nodes, and may be even more accurate than CT scan [29]. The experience of using EUS-FNA in changes located in the mucosa and submucosa are limited to small groups of patients $[1,7,9]$. One of the largest EUS-FNA series was carried out on 103 changes from the wall of the gastrointestinal tract (with the exception of stromal tumours) [28]. The sensitivity depends on the type of change: $89 \%$ for nonHodgkin's lymphoma of the stomach compared to $40 \%$ for adenocarcinoma of the stomach. Endoscopic ultrasound-fine needle aspiration of changes in the intestinal wall was correct in 24 (67\%) of 36 cases, in which classical endoscopic biopsies previously failed. The combined use of cytological and immunohistochemical analysis may allow for the diagnosis of some GIST. In a study of 65 patients undergoing EUS-FNA because of submucosal changes of the upper gastrointestinal tract within 4 years, EUS-FNA in conjunction with the cytological and immunohistochemical analysis of received material was diagnostic in 45 (68\%) of 66 changes, indicated suspicion in $8(12 \%)$, and was nondiagnostic in 13 (20\%) [31]. The sensitivity of EUSFNA in the diagnosis of GIST was $82 \%$ with specificity of $100 \%$ among the 28 lesions with the final pathological diagnosis. Additionally, biopsy of solid changes in the liver can be made with the EUS via the stomach [28]. Endoscopic ultrasound-fine needle aspiration of adrenal mass has been described in patients where other biopsy methods failed. Endoscopic ultrasoundfine needle aspiration can diagnose lesions of proximal bile structures after the negative ERCP and brush cytology. It is very important that FNA has a "short road" of needle puncture, which results in reduction of the risk of implanting the cancer cells into other organs. It is a great advantage compared with percutaneous puncture.

\section{Endoscopic ultrasound complications}

The most common side effects are associated with the necessity of carrying out EUS during sedation. The prevalence of $\mathrm{SaO}_{2}$ reduction $<80 \%$ is at the level of $0.4 \%$ [32]. The use of deep sedation with propofol is as safe as the application of midazolam and pethidine [33]. On the other hand, the most common complication resulting directly from the study is perforation. The interruption of the continuity of the digestive tract is most often around the hypopharynx, hiatal hernia, duodenum, or rectovaginal-sigmoid connection, when unexpected anatomical changes like diverticula of the oesophagus or duodenum, or neoplastic infiltration are encountered. Perforation of the oesophagus, which represents $68 \%$ of all perforations, is estimated at $0.03 \%$ of all performed procedures. The greatest risk occurs in the cervical oesophagus, in older patients with a history of difficult intubation, large osteophytes, or when EUS is conducted by an inexperienced endoscopist (performing EUS $<12$ months or $<300$ studies) [34]. Most of these patients (77\%) passed before EUS widening of the oesophagus, usually in the course of neoplastic infiltration. Prospective analysis shows comparable frequency (0.009-0.03\%) of oesophageal perforation after EUS in observations of 3 and 7 years, respectively, depending on the medical centre in which the examination was performed [35]. Duodenal perforation is the second most common location of breaking the wall of the gastrointestinal tract during EUS. Most often it is associated with the occurrence of diverticulitis, stenosis, or pancreatic head tumour. Only German data describes its higher frequency than perforation of the oesophagus (0.022 vs. 0.009) [36]. In contrast to the perforation of the oesophagus, where the most non-invasive strategy should be applied, the treatment of duodenal perforation required 99\% surgical intervention. Extending the diagnosis of EUS-FNA in pancreatic cancer increases the incidence of duodenal perforation to $0.86 \%$. Other locations of perforation, usually the stomach and rectum, are even rarer and are almost always associated with narrowing infiltration of the lumen by the tumour [36]. A release of cancer cells in the blood after transrectal diagnostic ultrasound (TRUS) performed to rectal cancer staging has not been well examined yet. An increasing number of circulating tumour cells was found in $24 \%$ of the TRUS, although a comparative study revealed similar spreading in 38\% of patients before the test [37]. Use of EUS-FNA is associated with approximately 10-times higher (0.98\%) risk of complications compared to non-invasive EUS. The most common are pain (34\%), pancreatitis (34\%), infections (16\%), bleeding (13\%), and rarely perforation or leakage of bile (3\%) [38]. The risk of bleeding after EUS-FNA, which is usually self-limiting, is about $4.4 \%$. The total risk of pancreatitis after EUS-FNA of solid tumours of the pancreas is $0.29 \%$, infection after cysts' aspiration is $14 \%$, but the use of prophylactic antibiotics reduced it to $0.3 \%$. The risk of bacteraemia appears to be very low, even in the case of biopsy of rectal and perirectal solid tumours [32]. However, antibiotic prophylaxis is recommended prior to FNA of cystic changes. The 
frequency of complications after biopsy of pancreatic cysts appear to be similar to those observed after the biopsy of solid tumours. In a group of 603 patients, complications were found in 13 of them (2\%) [39]. Celiac plexus neurolysis during EUS can cause temporary symptoms lasting less than $48 \mathrm{~h}$ : abdominal pain $(9 \%)$, diarrhoea (17\%), and a decrease in diastolic blood pressure for approximately $30 \mathrm{~min}(20 \%)$ [40].

\section{Acknowledgments}

This publication was created as part of the Regional Programme National Cohesion Strategy: The project "Creation of unique in Świętokrzyskie endosonography unit - EUS, in order to begin performing research", was co-financed by the European Union from the European Regional Development Fund under the Regional Operational Programme of Świętokrzyskie for the years 2007-2013.

\section{Conflict of interest}

The authors declare no conflict of interest.

\section{References}

1. Nowicki A. Ultradźwięki w medycynie: wprowadzenie do współczesnej ultrasonografii. Roztoczańska Szkoła Ultrasonografii, Warsaw 2010; 9-19, 22-5, 55-6.

2. Polkowski M, Bergman JJ. Endoscopic ultrasonographyguided biopsy for submucosal tumors: needless needling? Endoscopy 2010; 42: 324-6.

3. Hwang JH, Saunders MD, Rulyak SJ, Shaw S, Nietsch H, Kimmey MB. A prospective study comparing endoscopy and EUS in the evaluation of GI subepithelial masses. Gastrointest Endosc 2005; 62: 202-8.

4. Kojima T, Takahashi H, Parra-Blanco A, Kohsen K, Fujita R. Diagnosis of submucosal tumor of the upper GI tract by endoscopic resection. Gastrointest Endosc 1999; 50: 516-22.

5. Karaca C, Turner BG, Cizginer S, Forcione D, Brugge W. Accuracy of EUS in the evaluation of small gastric subepithelial lesions. Gastrointest Endosc 2010; 71: 722-7.

6. Polkowski M, Regula J, Tilszer A, Butruk E. Endoscopic ultrasound versus endoscopic retrograde cholangiopancreatography for patients with intermediate probability of bile duct stones: a randomized trial comparing two management strategies. Endoscopy 2007; 39: 296-303.

7. Williams EJ, Green J, Beckingham I, Parks R, Martin D, Lombard M; British Society of Gastroenterology: Guidelines on the management of common bile duct stones (CBDS). Gut 2008; 57: 1004-21.

8. Baron TH, Irani S. Prevention of post-ERCP pancreatitis. Minerva Med 2014; 105: 129-36.

9. Tse F, Liu L, Barkun AN, Armstrong D, Moayyedi P. EUS: a metaanalysis of test performance in suspected choledocholithiasis. Gastrointest Endosc 2008; 67: 235-44.

10. Aube C, Delorme B, Yzet T, Burtin P, Lebigot J, Pessaux P, Gondry-Jouet C, Boyer J, Caron C. MR cholangiopancreatography versus endoscopic sonography in suspected common bile duct lithiasis: a prospective, comparative study. AJR Am J Roentgenol 2005; 184: 55-62.

11. Kawakubo K, Kawakami H, Kuwatani M, Haba S, Kudo T, Abe Y, Kawahata S, Onodera M, Ehira N, Eto K, Sakamo- to N. Safety and utility of single-session endosopic ultrasonography and endoscopic retrograde cholangiopancreatography for the evaluation of pancreatobiliary disease. Gut Liver 2014; 8: 329-32.

12. Petrov MS, Savides TJ. Systematic review of endoscopic ultrasonography versus endoscopic retrograde cholangiopancreatography for suspected choledocholithiasis. $\mathrm{Br}$ J Surg 2009; 96: 967-74.

13. Fritscher-Ravens A, Brand L, Knöfel WT, Bobrowski C, Topalidis T, Thonke F, de Werth A, Soehendra N. Comparison of endoscopic ultrasound-guided fine needle aspiration for focal pancreatic lesions in patients with normal parenchyma and chronic pancreatitis. Am J Gastroenterol 2002; 97: 2768-75.

14. Giovannini M, Thomas B, Erwan B, Christian P, Fabrice C, Benjamin E, Geneviève M, Paolo A, Pierre D, Robert Y, Walter S, Hanz S, Carl S, Christoph D, Pierre E, Jean-Luc VL, Jacques D, Peter V, Andrian S. Endoscopic ultrasound elastography for evaluation of lymph nodes and pancreatic masses: a multicenter study. World J Gastroenterol 2009; 15: 1587-93.

15. Mizuno N, Bhatia V, Hosoda W, Sawaki A, Hoki N, Hara K, Takagi T, Ko SB, Yatabe Y, Goto H, Yamao K. Histological diagnosis of autoimmune pancreatitis using EUS-guided trucut biopsy: a comparison study with EUS-FNA. J Gastroenterol 2009; 44: 742-50.

16. Bhutani MS, Arantes VN, Verma D, Moezzi J, Suryaprasad S, Kapadia AS, Gopalswamy N. Histopathologic correlation of endoscopic ultrasound findings of chronic pancreatitis in human autopsies. Pancreas 2009; 38: 820-4.

17. Albashir S, Stevens T. Endoscopic ultrasonography to evaluate pancreatitis. Cleve Clin J Med 2012; 79: 202-6.

18. Albashir S, Bronner MP, Parsi MA, Walsh RM, Stevens T. Endoscopic ultrasound, secretin endoscopic pancreatic function test, and histology correlation in chronic pancreatitis. Am J Gastroenterol 2010; 105: 2498-503.

19. Yusoff IF, Sahai AV. A prospective, quantitative assessment of the effect of ethanol and other variables on the endosonographic appearance of the pancreas. Clin Gastroenterol Hepatol 2004; 2: 405-9.

20. Irisawa A, Mishra G, Hernandez LV, Bhutani MS. Quantitative analysis of endosonographic parenchymal echogenicity in patients with chronic pancreatitis. J Gastroenterol Hepatol 2004; 19: 1199-205.

21. Hirooka Y, Goto H, Ito A, Hayakawa S, Watanabe Y, Ishiguro Y, Kojima S, Hayakawa T, Naitoh Y. Contrast-enhanced endoscopic ultrasonography in pancreatic diseases: a preliminary study. Am J Gastroenterol 1998; 93: 632-5.

22. Matsuda T, Marugame T, Kamo K, Katanoda K, Ajiki W, Sobue T; Japan Cancer Surveillance Research Group. Cancer incidence and incidence rates in Japan in 2005: based on data from 12 population-based cancer registries in the Monitoring of Cancer Incidence in Japan (MCIJ) project. Jpn J Clin Oncol 2011; 41: 139-47.

23. Larghi A, Verna EC, Lecca PG, Costamagna G. Screening for pancreatic cancer in high-risk individuals: a call for endoscopic ultrasound. Clin Cancer Res 2009; 15: 1907-14.

24. Polkowski M, Palucki J, Wronska E, Szawlowski A, Nasierowska-Guttmejer A, Butruk E. Endosonography versus helical computed tomography for locoregional staging of gastric cancer. Endoscopy 2004; 36: 617-23.

25. Gill KR, Ghabril MS, Jamil LH, McNeil RB, Woodward TA, Raimondo M, Hoffman BJ, Hawes RH, Romag- 
nuolo J, Wallace MB. Endosonographic features predictive of malignancy on FNA in lung cancer-associated mediastinal lymph nodes. Gastrointest Endosc 2010; 72: 265-71.

26. Iglesias-Garcia J, Poley JW, Larghi A, Giovannini M, Petrone MC, Abdulkader I, Monges G, Costamagna G, Arcidiacono P, Biermann K, Rindi G, Bories E, Dogloni C, Bruno M, Dominguez-Muñoz JE. Feasibility and yield of a new EUS histology needle: results from a multicenter, pooled, cohort study. Gastrointest Endosc 2011; 73: 1189-96.

27. Wallace MB, Kennedy T, Durkalski V, Eloubeidi MA, Etamad R, Matsuda K, Lewin D, Van Velse A, Hennesey W, Hawes RH, Hoffman BJ. Randomized controlled trial of EUS-guided fine needle aspiration techniques for the detection of malignant lymphadenopathy. Gastrointest Endosc 2001; 54: 441-7.

28. Chen AM, Thosani NC, Friedland S, Banerjee S. 99 Prospective randomized blind controlled trial of capillary EUS-FNA vs. suction EUS-FNA for the diagnosis of solid tumors. Gastrointest Endosc 2014; 79 Suppl.: AB111.

29. Wiersema MJ, Vilmann P, Giovannini M, Chang KJ, Wiersema LM. Endosonography-guided fine-needle aspiration biopsy: diagnostic accuracy and complication assessment. Gastroenterology 1997; 112: 1087-95.

30. Chang KJ, Nguyen P, Erickson RA, Durbin TE, Katz KD. The clinical utility of endoscopic ultrasound-guided fineneedle aspiration in the diagnosis and staging of pancreatic carcinoma. Gastrointest Endosc 1997; 45: 387-93.

31. Lumsden A, Bradley EL 3rd. Pseudocyst or cystic neoplasm? Differential diagnosis and initial management of cystic pancreatic lesions. Hepatogastroenterology 1989; 36: 462-6.

32. Watson RR, Binmoeller KF, Hamerski CM, Shergill AK, Shaw RE, Jaffee IM, Stewart L, Shah JN. Yield and performance characteristics of endoscopic ultrasound-guided fine needle aspiration for diagnosing upper GI tract stromal tumors. Dig Dis Sci 2011; 56: 1757-62.

33. Gottschalk U, Dffelmeyer M, Jenssen C. [Komplikationserfassung der diagnostischen und therapeutischen Endosonografie]. Z Gastroenterol 2011; 49: V118.

34. Dewitt J, McGreevy K, Sherman S, Imperiale TF. Nurse administered propofol sedation compared with midazolam and meperidine for EUS: a prospective, randomized trial. Gastrointest Endosc 2008; 68: 499-509.

35. Lachter J. Fatal complications of endoscopic ultrasonography: a look at 18 cases. Endoscopy 2007; 39: 747-50.

36. Mortensen MB, Fristrup C, Holm FS, Pless T, Durup J, Ainsworth AP, Nielsen HO, Hovendal C. Prospective evaluation of patient tolerability, satisfaction with patient information, and complications in endoscopic ultrasonography. Endoscopy 2005; 37: 146-53.

37. Jenssen C, Faiss S, Nürnberg D. [Complications of endoscopic ultrasound and endoscopic ultrasound-guided interventions - results of a survey among German centers]. Z Gastroenterol 2008; 46: 1177-84.

38. Koch M, Antolovic D, Kienle P, Horstmann J, Herfarth C, von Knebel Doeberitz M, Weitz J. Increased detection rate and potential prognostic impact of disseminated tumor cells in patients undergoing endorectal ultrasound for rectal cancer. Int J Colorectal Dis 2007; 22: 359-65.

39. Wang KX, Ben QW, Jin ZD, Du YQ, Zou DW, Liao Z, Li ZS. Assessment of morbidity and mortality associated with EUS guided FNA: a systematic review. Gastrointest Endosc 2011; 73: 283-90.
40. Gunaratnam NT, Sarma AV, Norton ID, Wiersema MJ. A prospective study of EUS-guided celiac plexus neurolysis for pancreatic cancer pain. Gastrointest Endosc 2001; 54: 316-24.

\section{Address for correspondence:}

\section{Jacek Kiełtucki MD, PhD}

Department of Internal Medicine and Endoscopy Unit Independent Public Health Care Center ul. 11 listopada 78, 28-200 Staszów, Poland

Phone: +48604966 301

E-mail: kieltuckijacek@op.pl 